\title{
Chinese-English Translation of Tourism Text Based on the Conceptual Blending Theory*
}

\author{
Julin $\mathrm{Xu}$ \\ Jiangxi University of Applied Science \\ Nanchang, China
}

\author{
Xiangying $\mathrm{Tu}$ \\ Jiangxi University of Applied Science \\ Nanchang, China
}

\author{
Qian $\mathrm{He}$ \\ Nanchang Business College of JAU \\ Nanchang, China
}

\begin{abstract}
Tourism translation is not only a simple transformation between two languages, but also a crosscultural communication activity, involving the nature, geography, architecture, history, folk culture and other aspects. This paper aims to apply the Conceptual Blending Theory to analyze the process of Chinese-English translation of tourism text in order to reveal the translator's psychological cognitive model in the translation process. That is to say, the translator first cross-maps the input spaces onto the generic spaces, through composition, completion and elaboration, generates new meanings in the translated text space, which are finally converted into the target linguistic symbols.
\end{abstract}

Keywords-Conceptual Blending; Tourism Text; Source Space; Target Space; Emergent Space

\section{INTRODUCTION}

In recent years, as the second largest economy, a flood of tourists visit China, and tourism in China is flourishing. According to World Tourism Organization (WTO), China will become the world's largest tourist destination and the fourth largest tourists' source by 2020 (Jin Huikang, 2006: v). A focus of attention of the tourist industry is how to effectively introduce China's tourism resources in a foreign language. Tourism translation should belong to professional translation practice, covering tourism activities, tourism major and tourist industry. Generally speaking, "tourism translation is a cross-language, cross-community, intertemporal, cross-cultural, cross-psychology communication. Compared with other types of translation practice, its characteristics of cross-culture, cross- psychological communication are more direct, more prominent, more typical, and more comprehensive" (Chen Gang, 2004:59).

\section{Rationale OF CURRENT RESEARCH}

The Conceptual Blending Theory (CBT, also called the Concept Integration Theory), as the new development of the second generation of cognitive science, first proposed by Fauconnier, is on the basis of his "mental space" theory. The

*This paper is the phased result of the "Foreign Language Research Project of Jiangxi Colleges and Universities" (2014) (Project No.: 14WX216) issued by the Jiangxi Social Science Planning Office. prototypical integration network is divided into four mental spaces, "one for each of the input spaces, one for the blended space, and a generic space which represents abstract properties that apply to structure in all of the spaces" (Coulson \& Fauconnier, 1999: 2). The elements from the two input spaces correspond by the means of partial cross-space mapping, and they are selectively projected into the blended space, where an online, dynamic process of meaning construction is formed. The blended space succeeds partially to structures from the two input spaces, but has its own emergent structure. The generic space hereof offers abstract structure that is common to the two input spaces.

Fauconnier (1997:149-151) has summed up five main features of the conceptual blending theory: cross-space mapping, generic space, blend, selective projection and emergent structure. The blended space has emergent structure, which does not arise from the inputs. As "Fig. 1" shows, the square in the blend refers to the emergent structure. Emergent structure is built up in three correlative ways: composition, completion and elaboration.

In brief, a process, called "running the blend", occurs whenever we think and talk. Some of these principles are fused to the blend through completion, and new principles come up through successive dynamic completion and elaboration.

Mandelblit (1997), one of Fauconnier's students, initially applied the CBT to translation studies in his Creative and Schematic Aspects in Sentence Processing and Translation. $\mathrm{He}$ argued that sentence processing is actually a process of conceptual and linguistic blending; where a conceived event is integrated with a syntactic construction and the sentence interpretation starts with the blending configuration. He also emphasizes that one of important functions of grammar is to formally indicate various blending configuration, and to provide cues to the receiver in reconstructing linguistic blends. Meanwhile, Mandelblit pointed out a dual-blending process of translation: firstly, translators consciously unpack the source sentence into conceptual and linguistic input structures (which means the "disintegration" or "unpacking" process); secondly, the unpacked input structures are blended 
into target language's grammatical constructions( which means the "re-blending" process).

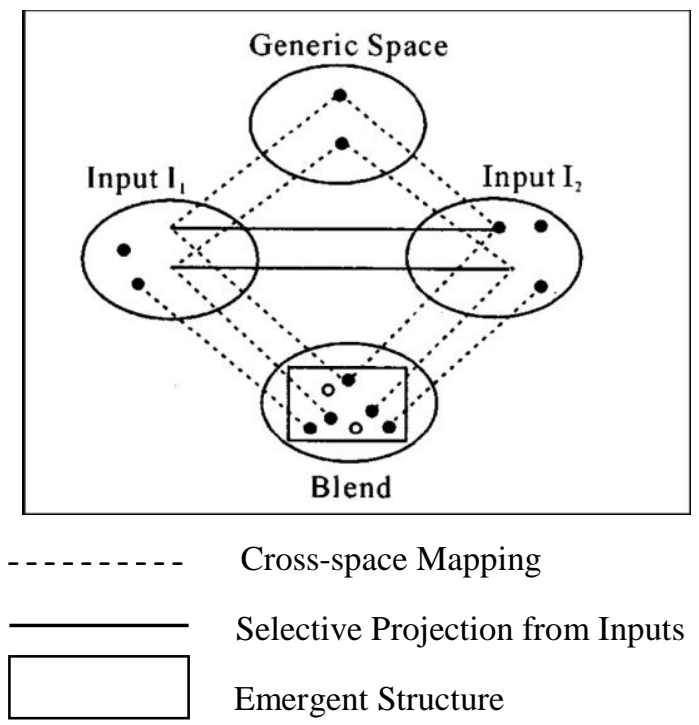

Fig. 1. Minimal Network of the CBT.

In the paper Conceptual Integration and Translation, Wang Bin (2001) agrees with Mandelblit's dual-blending process of translation, but criticizes that Mandelblit only put emphasis on explanation of metaphorical structure and domestication translational strategy. He gives us an additional blending, where the source space blends with the target space into a third space. Sun Ya (2001) believes that the translation process is a process of building two spaces (source space and translator's space), and translation as creative work is showed in the creative blended space. Dong Guirong \& Feng Qi (2005) argue that the elements from both source space and translator's inputs need to make semantic construction so as to produce the target version. In a word, all the relevant studies regard translation as an on-line or dynamic blending process, and propose some network models for translation.

Tourism translation is more complicated and comprehensive than other types of applied translation, because it involves not only bilingual transference, but also bi-social and bi-cultural transference. When translating tourist text, the translator is always influenced by lots of various factors. At present, scholars have conducted researches from the perspective of systemic-functional grammar, corpus-based approach, functionalist approach, skopos theory, aesthetics, sociolinguistics, pragmatic and cognitive approach or information science as well as intercultural communication. Many studies purport to elaborate the problems of tourism translation, and put forward translation strategies or skills based on the corresponding theoretical framework or empiricalism, which provide us with many valuable views for the further study. Nevertheless, the translator's dynamic thinking process while translating frequently is ignored. Therefore, the author attempts at exploring the translational cognitive process by applying the Conceptual Blending Theory (CBT) which have a great explanatory power.

\section{APPLICATION OF THE CONCEPTUAL BLENDING THEORY TO C-E TRANSLATION OF TOURISM TEXT}

Traditionally, translation is viewed as the linguistic conversion between the ST and the TT. With the translation study development, the role of translator has been more and more emphasized; the translator's translation competence is the key factor for a good translated text. The original tourism text, the relevant target language expressions and the translator's knowledge structure are deemed as the two input spaces in tourism translation, i.e. the TT is the integration of the SS (source space), where an integration of entrenched tourism text and the discourse is formed; and the TS (target space) is an integration of the translator's assimilating competence, cultural empathy competence, personal reference point and cognitive context, for example, the counterparts of cultural expression in target language. The GS (generic space), consisting of people's generic thinking way and the conceptual and grammatical structures shared by four spaces, makes linguistic switch between ST and TT possible. At the end, the TTS (translated text space) is composed of the BS (blended space) and an emergent structure.

Nowadays, with the development of tourism consumption level, besides six traditional factors: food, accommodation, communication and vehicle, traveling, shopping and entertainment, the physical fitness and education become unnecessary tourism activities, tourism text is characterized by the mixed style, combining colloquial with formal. Some are narrative; some are descriptive, or emotive and even poetic. Since tourism text aims at various people with different culture, educational backgrounds, different classes, and its language should be very characteristic, namely, vividness, conciseness and accuracy, figurative language, extensive use of adjectives and adverbs, use of pronoun without the third person

Tourism text has its own unique features; hence the translated texts should have source language's art attractiveness so as to achieve the commercial goal, and be adapted to the expectation of the reader. Since the target group's culture, mentality and actual demands, which are set up by source text's author, are different from those of the consumers under the conditions of target language, rewriting, interpretation or re-creation become inevitable.

Western mass communication proposes that tourism text should take the cognitive competences of target group into full consideration; however, Chinese people prefer to common and popularized texts, which cannot easily catch the target group's attention in market positioning. In view of the sino-western cognitive differences, some tourism texts will be discussed from the cognitive perspective, that is to say, the following part will apply the conceptual blending theory to the C-E translation of tourism texts, probing into the online or dynamic translating process. Some analyses will be shown below:

中西融和，无尽精彩 
今年，香港全力呈现包罗万象的节庆盛事，令气氛格外热闹高涨！ 中西庆典各显特色，娱乐、音乐、体育、艺术文化节目共冶一炉，规 模之大都是前所未见！快动身，感受香港独有好气氛！

Hong Kong a world of celebration

Come and discover Hong Kong's unique world of magical celebrations. Experience an enchanting mix of Chinese and Western festivities in a mesmerising yearround whirl of festivals, music, sports, arts and cultural events you'll find nowhere else.

After reading this tourism text about the festive season of Hong Kong, you will get excited, maybe impulse-purchase. The tourism text integrates all the elements of marketing very well, in the author's opinion, it can evoke the potential tourists or visitors' interest. Next, from the angle of translation, the author will probe into the dynamic cognitive translating process.

As the topic sentence of the tourism text, the wording "中 西融和，无尽精彩”"embodies the distinguishing feature of the festive season. However, it seems that no connections match each other between Chinese version and English version. In fact, the connections are not arbitrary but indirect. The translated English text covers some elements, which do not originate from source space. As usual, this type of text translation is regarded as a result of multiple blends. The Optimality Principles in conceptual integration are applied to explore the implied corresponding relationships, that is to say, the translator unpacks the source space, uses point of view shift and selectively projects the elements back to the input spaces; then, another way of composition, completion and elaboration are chosen to form a different blending space.

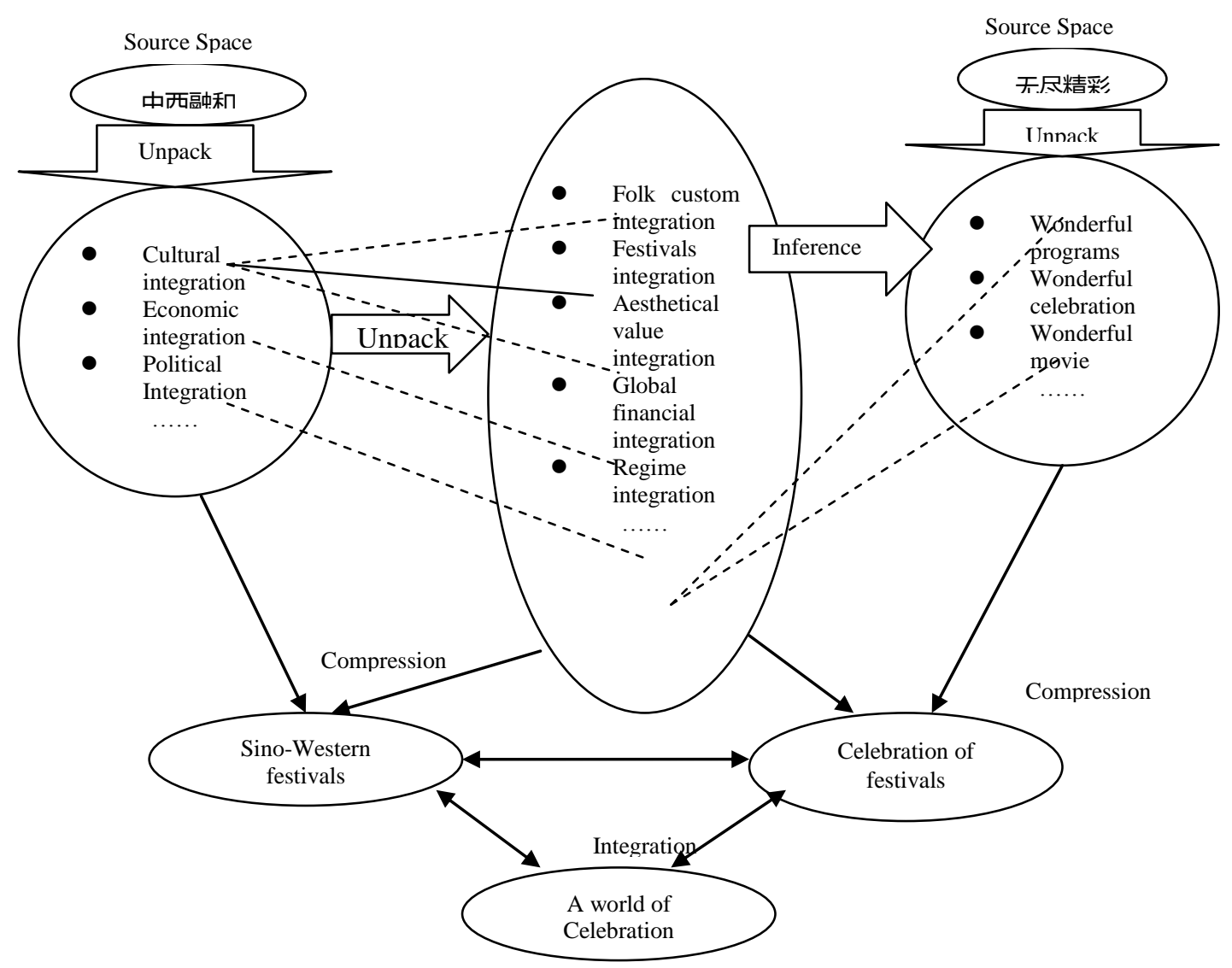

Fig. 2. Conceptual Integration Process in Translation of “中西融和，无尽精彩”.

As "Fig.2" shows, the complexity of multiple blends is included in the entire construction of network, such as links builder, selective projections, and cross-mappings from source space to target space. "Emergent structure" does not mean the conceptual structure of the blended space by itself, but rather the dynamic cognitive frame, especially the projections linking the input spaces to the blended spaces. Therefore, whether tourism translation is successful or not is decided by many factors, instead of single faithful degree to source text. For this topic sentence, the translator does not make literal translation, but adopts conceptual blending way.

In source text, the expression “中西融和” represents the sino-western cultural harmony in Hong Kong, through celebrating all the festivals of China and western countries. China plus western countries constitute a world; “无尽精 彩”can be inferred to be wonderful celebration, “中西融和” and “无尽精彩” are compressed the causal relationship; therefore, we infer "a world celebrating festivals". "When an element 
in one state is later in a different state, we can compress this into a space in which the element undergoes a change of state (Fauconnier \& Turner, 1998:164)." A change of state is referred to combination of non-counterparts in Conceptual Integration Network. In translated text, by the concrete wording "world", "celebration", the translator adopts direct expressions, which is contrary to Chinese spiral thinking way; this point embodies "a change of state". In the meantime, the translator does not translate word for word, but omits “无尽精 彩”, and stress "Hong Kong”- tourism destination. Two reasons are explained: firstly, in Chinese version, two parallel four-character structures can easily reach the textual structure balance, which conforms to Chinese expressing habit. Secondly, "Hong Kong" lies at the beginning, which can deepen the tourists' impression on tourism destination and accord with western people's direct thinking way.

For the main body of tourism text, Chinese version firstly juxtaposes narrative sentences, and then introduces one imperative sentence, so as to construct general concepts and vivid image. By contrast, English version mainly adopts imperative sentences, which will directly evoke the readers to take action and represent linear thinking way of western people. On a whole, C-E translation is not completely wordfor- word.

TABLE I. CONCEPTUAL STRUCTURES IN C-E TRANSLATION OF TOURISM TEXT 1

\begin{tabular}{|c|c|}
\hline Source Space & $\begin{array}{l}\text { Spiral thinking way } \\
\text { Celebrations distinguish features } \\
\text { Programs' scope } \\
\text { Evocation } \\
\text { NP+VP+A+NP, VP+A+NP, }\end{array}$ \\
\hline Target Space & $\begin{array}{l}\text { Direct or linear thinking way } \\
\text { Evocation } \\
\text { Programs' scope } \\
\text { Celebration distinguish features } \\
\text { VP+A+NP+ADV, NP+VP+ADV }\end{array}$ \\
\hline Generic Space & $\begin{array}{l}\text { VP +NP, } \\
\text { Agent, Acts, Object, Degree }\end{array}$ \\
\hline $\begin{array}{c}\text { Translated Text } \\
\text { Space }\end{array}$ & Highlighting the vocative function of tourism text \\
\hline
\end{tabular}

According to "Table I", there exists all counterparts between source space and target space, direct cross-space mappings like “特色”- “unique”, “前所未见” “find nowhere else”“音乐、体育、艺术文化节目”-“music， sports，arts and cultural event" etc., share the same conceptual structure in the generic space respectively. Under such circumstances, the translator can easily project the counterparts into translated text space; however, due to different thinking ways and translated text's acceptability, the translator cuts some repetition in meaning, and re-builds discourse in more logical or well-knit form.

\section{楚韵长河，千年书院}

惟楚有才，于斯为盛

Long-established tradition of Chu culture, thousand-yearold Academy

Hunan fosters talents with Yuelu Academy the best in ancient China (Jin Huikang, 2006:341)

This tourism text focuses on Chu culture, which is a perfect representative of Hunan tourism. The translator should firstly disintegrate Chinese version into a series of basic events “楚韵”, “书院”, “才”, which embody some vital relations of Hunan tourism. It will show the cognitive translating process.

As "Fig. 3" clearly shows, we know that the conceptual integration process represents unpacking and compression of the source text. Of course, unpacking is not simply a deconstruction but it is based on all the knowledge structure of the translator.

The two key elements of Hunan tourism-Chu culture, Yuelu Academy - have no counterparts in target space, there is no direct cross-space mapping. Under such circumstance, the translator chooses one element "talents" as a start point. During the conceptual integration process, two mental spaces “书院” and “才” are compressed into role and value relationship. Chinese readers can easily use composition, completion and elaboration to activate relevant bits of historical cultural knowledge to understand the connotation of Hunan unique culture. Nevertheless, western readers cannot find the corresponding cultural information in their knowledge structure. Hence the translator compresses and integrates the conceptual structure "Yuelu Academy fostered the best talents in ancient China", which put western readers into a context "Yuelu Academy is related with talents".

On the other hand, the translator does not translate word for word, but takes the target language readers' acceptability and conceptual structure into full consideration. “长河”into “long-established tradition" not "long river"; “于斯为盛”, as a typical ancient Chinese form, into the meaning "the best talents”, emphasizing the meaning“盛”; and “楚” directly represents "Hunan".

From the perspective of grammatical structure, the translator adopts the similar grammatical form, which conforms to English expressive tradition, to convey the key concept of Hunan tourism. 


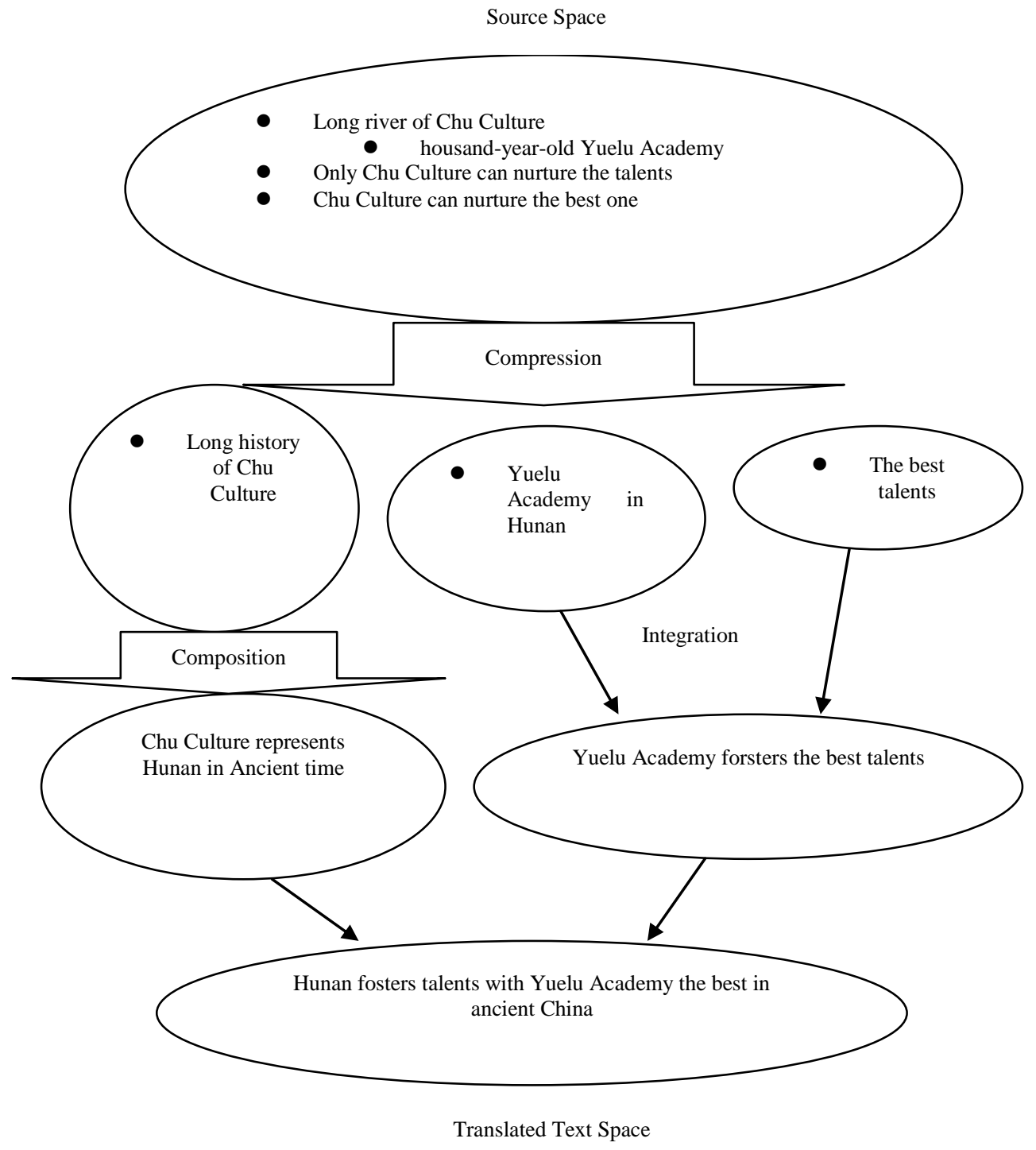

Fig. 3. Conceptual Integration Process in Translation of Tourism Text 2.

\section{CONCLUSION}

In view of the uniqueness, diversity and complexity of tourism text translation, it is quite a hard job for the translator to master it very well. Hence the tourism translation study in this paper has special academic significance.

Firstly, it is a new perspective to combine the Conceptual Blending Theory with applied translation study; new translation model will complement the shortage of the previous translation models. Secondly, to probe into tourism translation process is quite different from previous tourism translation studies, which have been conducted from perspective of language structure, rhetorical phenomena or cultural background. This study will be lightening to the translators and be conductive to the quality improvement of translated tourism text. Thirdly, further applications prove the feasibility of the Conceptual Blending Theory in translation.
It is hoped that more and more scholars will pay more attention to tourism development as well as the tourism text translation, and more fresh insights will come into being in the future. In the meantime, further systematic and comprehensive studies are expected, so as to give practical suggestions for wider range of applied translation studies.

\section{REFERENCES}

[1] Andre, J. S. (2006).Traveling toward true translation: The first generation of Sino-English translation. [J] The Translator, 12(2), 189-210.

[2] Eugene Nida. Language, Culture and Translating [M]. Shanghai Foreign Language Education Press, 1993.

[3] Fauconnier Gilles \& Turner Mark. Conceptual Integration Networks [J]. Cognitive Science: 1998, 22, 133-187.

[4] Fauconnier G., Turner, M. The Way We Think: Conceptual Blending and the Mind's Hidden Complexities [M]. New York: Basic Books, 2002. 
[5] Fauconnier G. Mapping in Thought and Language [M]. Cambridge: Cambridge University Press, 1997.

[6] Newmark. P. A Textbook of Translation [M].Shanghai: Shanghai Foreign Language Education Press. 2001:85,113.

[7] Mandelblit, Nili, (1995).The Cognitive View of Metaphor and its Implications for Translation Theory [M].Maastricht: Universitaire Press.

[8] Newmark. P. Approach to Translation [M]. Shanghai: Shanghai Foreign Language Education Press. 2001.

[9] Turner M. Reading Mind: The Study English in the Age of Cognitive Science [M]. Princeton University Press, 1991.

[10] Chen Gang. Tourism Translation and Guide-interpreter [M], China Translation Corporation, 2004.

[11] Jin Huikang. Translation in Intercultural Tourism [M], China Translation Corporation, 2006: 341.

[12] Dong Guirong, Fengqi. On Rationality of Translation Creation from the Perspective of Conceptual Integration [J]. Shanghai Journal of Translators, 2005(S1):33-36.

[13] Miao Ju, Wang Shaoshuang. Exploring Translational Norms in Light of Conceptual Integration Theory [J], Foreign Languages in China, 2014 (1): 94-99.

[14] Wang Yin. Cognitive Linguistics [M]. Shanghai: Shanghai Foreign Language Education Press.2007.

[15] Wang Yin. A Cognitive Linguistic View on Translation [J]. Chinese Translators Journal, 2005 (5):15-20.

[16] Wang Zhengyuan. Development of Conceptual Blending and its Frontier Issues [J], Journal of Sichuan International Studies University, 2006 (6).

[17] Wang Zhengyuan. Conceptual Integration Theory and its Applied Research/Cognitive Linguistic Research [M], High Education Press, 2009.

[18] Wang Bin. Conceptual Integration and Translation [J], Chinese Translators Journal, 2001 (3).

[19] Wang Bin. Blending Theoretic Account of Translation under Metaphoric Structures [J], Chinese Translators Journal, 2002 (2).

[20] Wang Bin. Translation and Conceptual Integration [M], Shanghai: Donghua University Press, 2004.

[21] Sun Ya. Mental Space Theory and Translation [J].Shanghai Journal of Translator for Science and Technology, 2001 (4):12-14.

[22] http://www.discoverhongkong.com 